\title{
Effects of prime-target spatial separation and attentional deployment on masked repetition priming
}

\author{
YousRi MARzouki \\ Aix-Marseille University, Marseille, France \\ MARTIJN MEeTer \\ Vrije Universiteit Amsterdam, Amsterdam, The Netherlands \\ AND \\ JonATHAN GraingER \\ Aix-Marseille University, Marseille, France, \\ and LPC, CNRS, UMR 6146, Aix-en-Provence, France
}

\begin{abstract}
In two masked repetition priming experiments with letter stimuli, the positions of prime and target stimuli were varied horizontally from fixation. Priming effects did not interact with position when prime and target location covaried (Experiment $1 \mathrm{~A}$ ) but diminished with increasing prime eccentricity when targets were always centrally located (Experiment 1B). Two accounts of this pattern of priming effects were proposed that postulate two different mechanisms over and above effects of visual acuity. The integration account postulates degree of separation of prime and target stimuli as the critical factor, and the attentional account postulates spatial attention as the critical factor. The results of Experiment 2, in which prime and target positions were manipulated orthogonally, were in favor of the attentional account. Repetition priming did not vary as a function of whether or not primes and targets appeared at the same location, but target processing was facilitated independently of priming when targets appeared at the same location as primes, especially in the right visual field.
\end{abstract}

Since its inception in the early 1980 s, the masked repetition priming paradigm has become a dominant tool in the investigation of perceptual processes involved in letter and word recognition (e.g., Forster \& Davis, 1984; Holcomb \& Grainger, 2006; Jacobs \& Grainger, 1991; Segui \& Grainger, 1990). In the vast majority of masked priming studies, both the prime and target stimuli are presented at fixation. In one of the first studies to break with this tradition, Marzouki and Grainger (2008) investigated repetition priming effects with word stimuli while parametrically manipulating prime and target eccentricity. Marzouki and Grainger placed either prime and target stimuli (Experiment 1A) or only prime stimuli (Experiments 1B and 2) at several positions along the horizontal meridian. Reaction times (RTs) increased with increasing target eccentricity. Most important, however, is that priming effects were also found to vary with eccentricity, with the strongest priming appearing at the most central locations. Furthermore, priming effects tended to be more restricted with centrally located targets than when targets appeared at the same peripheral location as the primes, and they were stronger for primes in the right visual field (RVF) compared with the left visual field (LVF). Marzouki and Grainger showed that this pattern was not driven by eye movements and was robust in conditions in which prime stimuli were subliminal, as determined by a visibility test. Finally, a similar pattern of priming effects was also found for pseudoword targets.

Marzouki and Grainger's (2008) findings of information extraction from the periphery and of hemispheric asymmetry are consistent with our current understanding of the reading process. Contemporary models of reading all assume that while the eyes are fixating one word, words to the right of fixation are also being analyzed to some extent (E-Z Reader model-Reichle, Rayner, \& Pollatsek, 1999; SWIFT model-Engbert, Nuthmann, Richter, \& Kliegl, 2005). Such parafoveal preprocessing gives rise to parafoveal priming effects, whereby a "prime" stimulus situated immediately to the right of a fixated word affects the processing of the "target" word that appears at the prime location as soon as the eyes move to that location (e.g., Inhoff, 1989; Pollatsek, Lesch, Morris, \& Rayner, 1992). Parafoveal priming is proof that information can be extracted from the parafovea. However, in the E-Z Reader and SWIFT models,

Y. Marzouki, yousri.marzouki@univ-provence.fr 
very different mechanisms are proposed to account for parafoveal processing. In E-Z Reader, parafoveal processing occurs following an attention shift to the to-befixated location while an eye movement is programmed in order to shift the eyes to that location. In SWIFT, there is no attention shift, and parafoveal processing is simply the result of parallel processing that extends beyond the fixated word.

The present study examines the possible role of attention in enabling extraction of information from the parafovea and beyond. More precisely, we will examine two different ways of interpreting the pattern of results found by Marzouki and Grainger (2008), both of which appeal to basic mechanisms utilized in current models of reading. Both accounts agree that stimulus eccentricity (the distance from fixation of prime and target stimuli) is an important factor influencing how much information can be extracted from a stimulus, but they differ in terms of what other factors are at play. In the first account (the integration account), the other critical factor is the distance separating prime and target stimuli. This factor would reflect fundamental limitations in our ability to integrate information across space (i.e., the limits of translation invariance). In the second account (the attentional account) the critical extra factor is attention directed to the stimuli (prime and target). According to this account, differences in priming effects as a function of the distance separating prime and target stimuli do not reflect limits in translation invariance, but rather differences in the amount of attention allocated to prime stimuli. Although Marzouki and Grainger favored an integration account of their results, there are a number of recent experiments showing attentional influences on masked repetition priming (Besner, Risko, \& Sklair, 2005; Lachter, Forster, \& Ruthruff, 2004; Marzouki, Grainger, \& Theeuwes, 2007). These studies have all shown that when primes and targets occupy distinct spatial locations, masked repetition priming effects only arise when attention is drawn to the prime location. It is therefore possible that part of the influence of eccentricity found in Marzouki and Grainger's study could be due to differences in the amount of attention directed to (subliminal) prime stimuli when (visible) targets are always centrally located.

The present study puts these two accounts to the test. First, we replicate the work of Marzouki and Grainger (2008) using single letters as primes and targets. The use of single letters as opposed to words provides a stronger test of the integration account of priming effects obtained with primes and targets at different locations. With word stimuli, primes and targets partially overlapped at all but the largest prime eccentricity $\left( \pm 6^{\circ}\right)$. Using similar eccentricities with letter stimuli, there is never any overlap between centrally located targets and peripheral primes. Second, we introduce a novel manipulation of target eccentricity independently of prime eccentricity. If spatial integration of prime and target stimuli can occur across a region of central vision, then we ought to observe priming effects with target locations off fixation and prime stimuli at a different location within this critical zone.

\section{EXPERIMENT 1}

\section{Method}

Participants. Fifteen individuals in Experiment 1A (mean age 5 24 years) and 16 individuals in Experiment $1 \mathrm{~B}$ (mean age 521 years), psychology students, voluntarily participated in the study. All of the participants in Experiment 1A were right-handed, and there was only 1 left-handed participant in Experiment 1B. The participants all reported having normal or corrected-to-normal vision.

Design and Stimuli. Sixteen letters (all consonants) served as targets, along with 16 pseudoletters designed using Font Creator 4.0 software. Each target letter/pseudoletter was primed either by the same letter/pseudoletter (repetition prime) or a different letter/ pseudoletter (unrelated prime), defining the two levels of the factor prime relatedness. Letter targets were always primed by a letter, and pseudoletter targets were always primed by a pseudoletter. Prime and target stimuli could appear at seven different positions along the horizontal meridian: $-7^{\circ}$ (extreme left) $-4.7^{\circ},-2.3^{\circ}, 0^{\circ}$ (foveal position) $+2.3^{\circ},+4.7^{\circ}$, and $+7^{\circ}$ (extreme right). In Experiment $1 \mathrm{~A}$, prime and target stimuli always appeared at the same location. In Experiment $1 \mathrm{~B}$, prime position was manipulated and targets always appeared centrally. Eccentricity was crossed with repetition in a $7 \times 2$ factorial design. Each letter/pseudoletter target was seen twice by each participant, once in the repetition prime condition and once with an unrelated prime, for a total of 448 trials.

Procedure. The experiment was run in a dimly lit room and was controlled using DMDX software (Forster \& Forster, 2003). Participants were seated in front of a computer screen on which stimuli were displayed in VGA mode $(75-\mathrm{Hz}$ refresh) in white on a black background. The background luminance of the screen was approximately $0.01 \mathrm{~cd} / \mathrm{m}^{2}$ and the luminance of all stimuli was approximately $5.1 \mathrm{~cd} / \mathrm{m}^{2}$. The procedure is described in Figure 1. Each trial began with a central fixation point (a cross) for $2,000 \mathrm{msec}$. The fixation point was then replaced by a forward mask for $10 \mathrm{msec}$, consisting of a string of seven hash marks, each mark occupying one of the seven eccentricity positions. Prime stimuli appeared immediately after this, for a duration of $50 \mathrm{msec}$, and were followed by a backward mask (similar to the forward mask) lasting $10 \mathrm{msec}$. This was replaced by the target stimulus, which remained on the screen until the participant's response. The reported visual angles for each level of eccentricity define the distance between the central fixation location and the center of the stimulus at a viewing distance of $80 \mathrm{~cm}$. Participants were asked to respond as rapidly and as accurately as possible by pressing one of two joystick triggers with their index fingers: right button for letters and left button for pseudoletters. Manual response was counterbalanced across participants in order to avoid any influence of stimulus-response compatibility (i.e., a Simon effect; Simon, 1969). Participants first performed a practice session with a set of 16 letters and pseudoletters, followed by the 448 trials of the main experiment in random order. Participants were tested in either Experiment $1 \mathrm{~A}$ or $1 \mathrm{~B}$ in a session lasting approximately $30 \mathrm{~min}$.

\section{Results}

Figure 2 shows mean RTs as a function of prime eccentricity in Experiments $1 \mathrm{~A}$ and $1 \mathrm{~B}$ for letter targets. Participants responded with a high level of accuracy in both experiments (4\% error rate in Experiments $1 \mathrm{~A}$ and $2 \%$ error rate in Experiment 1B). RTs and percent errors were analyzed separately for Experiment $1 \mathrm{~A}$ and $1 \mathrm{~B}$ with a repeated measures 7 (eccentricity) $\times 2$ (repetition) ANOVA.

Experiment 1A. Results for the two analyses were as follows.

Letter analysis. There were main effects of eccentricity $\left[F(6,84)=3.72, M S_{\mathrm{e}}=1,348.77, p<.002\right]$ and repetition 


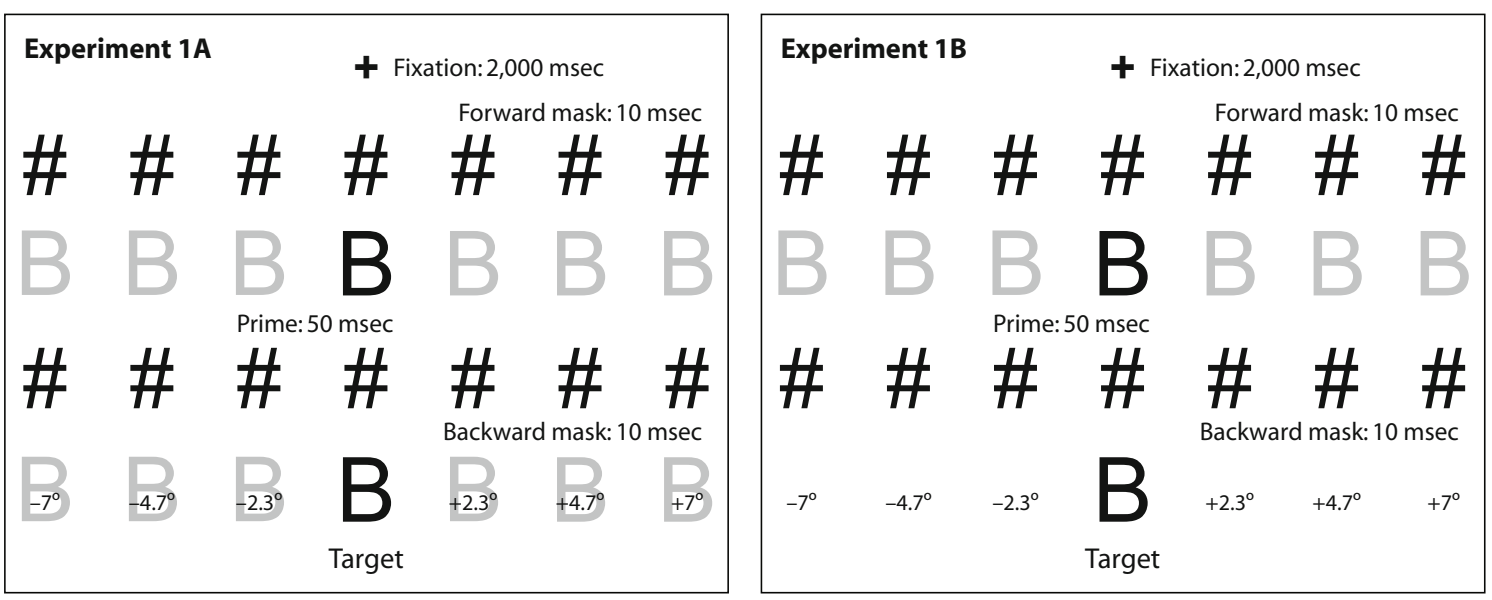

Figure 1. Experimental procedure used in Experiment 1A (left panel) where prime and target appear at the same location and in Experiment 1B (right panel) where the target is always centrally located. Prime stimuli occupied seven possible positions (from $-7^{\circ}$ to $+7^{\circ}$ ) defining seven levels of prime eccentricity. The eccentricity values (degrees of visual angle) represent the distance from fixation to the center of the prime/target stimulus.

$\left[F(1,14)=78.41, M S_{\mathrm{e}}=551.18, p<.0001\right]$, but no interaction $\left[F(6,84)=1.1, M S_{\mathrm{e}}=557.65, p>.1\right]$. Post hoc analyses showed significant differences between repeat and unrelated conditions at the following eccentricities: $-2.3^{\circ}(p<.05), 0^{\circ}(p<.05),+2.3^{\circ}(p<.003),+4.7^{\circ}$ $(p<.05)$, and $+7^{\circ}(p<.005)$. There were no main effects and there was no interaction in the ANOVA on the accuracy data. An ANOVA with the central position omitted and including visual field (left vs. right) as a factor showed no main effect of visual field $(F<1)$ but a significant interaction between visual field and repetition $\left[F(1,14)=5.23, M S_{\mathrm{e}}=398.42, p<.05\right]$, revealing that priming effects were larger in the RVF. There were no significant interactions between visual field and eccentricity $(F<1)$ or between eccentricity and priming $[F(2,28)=$ $\left.1.13, M S_{\mathrm{e}}=508.94, p>.1\right]$ and there was no three-way interaction $(F<1)$.

Pseudoletter analysis. Analyses on RTs revealed reliable main effects of eccentricity $\left[F(6,84)=4.27, M S_{\mathrm{e}}=\right.$ $1,723.92, p<.001]$ and repetition $[F(1,14)=11.35$, $\left.M S_{\mathrm{e}}=517.91, p<.005\right]$ but no interaction $(F<1)$. In the accuracy data, there was only a significant effect of eccentricity $\left[F(6,84)=2.62, M S_{\mathrm{e}}=0.26, p<.05\right]$.

Experiment 1B. For this experiment, the results were as follows.

Letter analysis. RTs increased with increasing eccentricity $\left[F(6,90)=2.76, M S_{\mathrm{e}}=520.92, p<.05\right]$. There was an effect of repetition $\left[F(1,15)=2.76, M S_{\mathrm{e}}=\right.$ $584.26, p<.0002]$, and repetition interacted with eccentricity $\left[F(6,90)=2.77, M S_{\mathrm{e}}=525.26, p<.05\right]$, with priming effects decreasing as prime eccentricity increased. Post hoc analyses showed robust priming effects at $0^{\circ}(p<.05)$ and $+2.3^{\circ}(p<.002)$. No significant main effects nor interaction were observed in the ANOVA on the accuracy data. A follow-up analysis of RTs with the central position omitted and including visual field (left vs. right) as a factor showed no main effect of visual field $(F<1)$ and no interaction between visual field and repetition $(F<1)$. Only the interaction between eccentricity and repetition was reliable $\left[F(2,30)=3.63, M S_{\mathrm{e}}=\right.$ $890.03, p<.05]$. The interaction between visual field and eccentricity was not significant $\left[F(2,30)=1.09, M S_{\mathrm{e}}=\right.$ $401.43, p>.1]$, nor was the triple interaction $[F(2,30)=$ $\left.1.91, M S_{\mathrm{e}}=361.96, p>.1\right]$.

Pseudoletter analysis. Analyses on RTs revealed reliable main effects of eccentricity $\left[F(6,90)=3.24, M S_{\mathrm{e}}=\right.$ $1,686.87, p<.01]$ and repetition $\left[F(1,15)=11.37, M S_{\mathrm{e}}=\right.$ $553.45, p<.05]$ but no interaction $(F<1)$. There were no significant effects in the accuracy data.

\section{Discussion}

Experiment 1 provides a replication of the results of Marzouki and Grainger (2008), obtained with letter stimuli as opposed to the word stimuli tested by Marzouki and Grainger (Figure 2). When primes and targets appeared at the same location, there was no interaction between priming and eccentricity (Experiment 1A). However, when only prime location varied (Experiment 1B), the size of repetition priming effects varied significantly as a function of prime eccentricity. The results of Experiment 1 therefore demonstrate that the pattern of priming effects reported by Marzouki and Grainger can be obtained with more spatially compact stimuli (single letters) for which there was never any overlap between primes and targets when they occupied different locations. Indeed, part of the priming effects observed by Marzouki and Grainger in these conditions could have been driven by the partial overlap between primes and targets facilitating integration processes. The results of the present Experiment 1B suggest that this was unlikely to be the case.

In the introduction, we presented two accounts of how the size of repetition priming effects might vary as a func- 


\section{Experiment 1A}
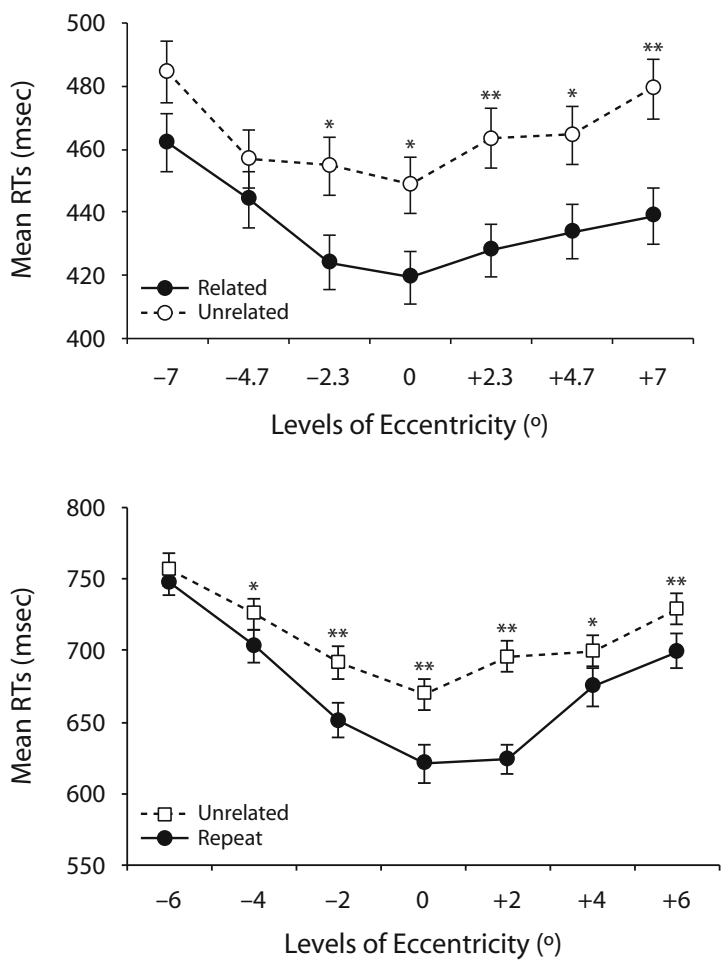

Experiment 1B
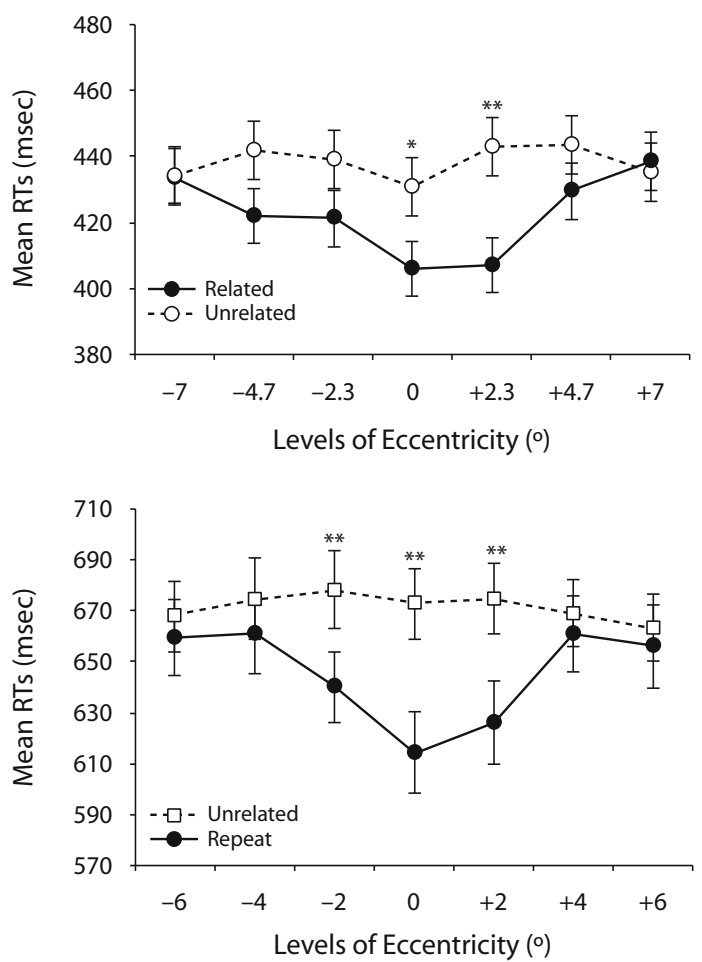

Figure 2. Upper panels: Mean reaction times (RTs) to letter targets as a function of prime condition (related/unrelated to target) and prime eccentricity in Experiment 1A (upper left panel: prime and target at same location) and in Experiment 1B (upper right panel: only prime location varied, central targets). Significant priming effects for a given level of eccentricity are indicated by asterisks $\left({ }^{*} p<\right.$ $\left..05 ;{ }^{* *} p<.01\right)$. Lower panels: Results of Experiment 1 from Marzouki and Grainger (2008) testing word targets in the lexical decision task in the same conditions.

tion of prime and target location. In the first account (the integration account), the critical factor determining the size of priming effects is the distance separating prime and target stimuli. Priming effects diminish as a function of prime eccentricity in Experiment $1 \mathrm{~B}$ due to the greater distance separating primes from centrally located targets. In the second account (the attentional account), the critical factor is attention directed to the stimulus (prime and target). According to this account, priming effects vary as a function of prime eccentricity in Experiment $1 \mathrm{~B}$ because of the diminishing amount of attention allocated to the prime location. Attention is assumed to be focused at fixation (where visible targets appear), tapering off as a function of eccentricity.

In explaining the results of Experiment 1B in Marzouki and Grainger (2008) and Experiment 1B in the present study, the integration account assumes that priming is smaller for eccentric prime locations because the distance between prime and target locations is large, leading to little overlap in the representations that support priming. The attentional account, on the other hand, assumes that attention is centered at fixation (where the observer expects the target), and that the lack of attention paid to the periphery is the cause of low levels of priming for eccentric primes. These two mechanisms would lead to different predictions if prime eccentricity and prime-target distance were to vary independently. Consider the case in which target and prime occur at the same eccentricity, either in the same or in different hemifields. The integration account would predict that priming would be larger when target and prime occur in the same hemifield, as opposed to in different hemifields. The attentional account, on the other hand, would predict that priming would be the same in both situations.

Experiment 2 was therefore designed to dissociate the confounding factors of prime eccentricity and prime-target spatial separation. If it is prime-target separation that is critical, we expect not to see any priming effects with primes at $2.3^{\circ}$ to the left of fixation and targets $2.3^{\circ}$ to the right (or vice versa), since this amount of prime-target separation $\left(4.6^{\circ}\right)$ did not yield significant priming in Experiment $1 \mathrm{~B}$. On the other hand, if it is prime eccentricity (from central fixation) that is critical, then we expect to observe priming effects in that condition, since primes at those eccentricities $\left(+2.3^{\circ}\right)$ were effective in Experiment $1 \mathrm{~B}$.

\section{EXPERIMENT 2}

\section{Method}

Participants. Ten individuals (mean age $=23$ years), psychology students, voluntarily participated in the study. All participants 


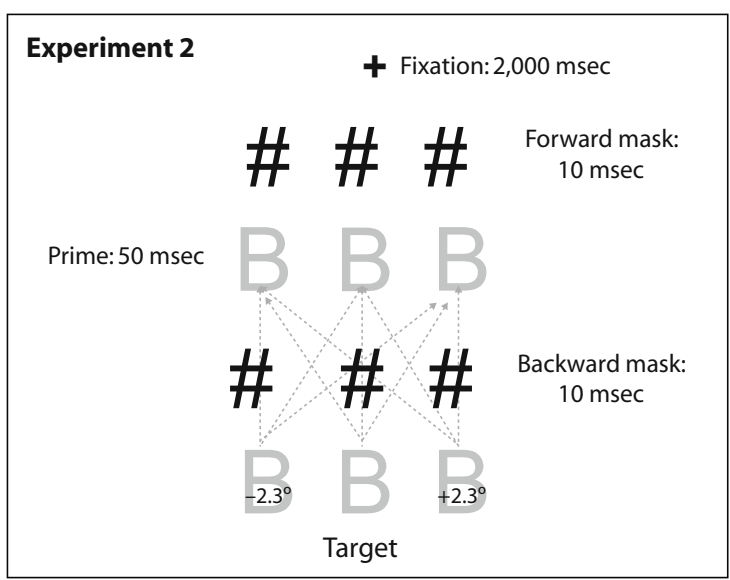

Figure 3. The structure of the experimental procedure of Experiment 2. Six different locations for stimuli: three for primes and three for targets. Arrows indicate the nine different combinations of prime and target location.

were right-handed and reported having normal or corrected-tonormal vision.

Design and Stimuli. Stimuli were the same as those used in Experiments 1A and 1B. Prime and target stimuli could appear at three different positions along the horizontal meridian (see Figure 3). Three factors were manipulated in this experiment: prime eccentricity $\left(-2.3^{\circ}, 0^{\circ}\right.$, and $\left.+2.3^{\circ}\right)$, target eccentricity $\left(-2.3^{\circ}, 0^{\circ}\right.$, and $+2.3^{\circ}$ ), and repetition (repeated vs. unrelated prime), in a $3 \times$ $3 \times 2$ factorial design.

Procedure. The procedure was the same as in Experiments 1A and $1 \mathrm{~B}$ except that primes and targets had independently varying locations in Experiment 2 (see Figure 3).

\section{Results}

Mean RTs obtained in Experiment 2 are presented in Figure 4 . The average error rate was $3.7 \%$.

Letter analysis. A repeated measures ANOVA with the following design was performed on RTs: prime eccentricity $\left(-2.3^{\circ}, 0^{\circ},+2.3^{\circ}\right) \times$ target eccentricity $\left(-2.3^{\circ}\right.$, $\left.0^{\circ},+2.3^{\circ}\right) \times$ repetition (repeat vs. unrelated). There was a main effect of repetition $\left[F(1,9)=33.23, M S_{\mathrm{e}}=421.54\right.$, $p<.0001]$ that was independent of prime and target locations (interaction $F_{\mathrm{S}}<1$ ). Results showed marginally significant effects for both prime eccentricity $[F(2,18)=$ $\left.3.09, M S_{\mathrm{e}}=342.71, p=.07\right]$ and target eccentricity $\left[F(2,18)=3.37, M S_{\mathrm{e}}=2,825.27, p=.06\right]$, with faster RTs at $0^{\circ}$ and $+2.3^{\circ}$. Only the interaction between target and prime eccentricity was significant $[F(4,36)=5.56$, $\left.M S_{\mathrm{e}}=554.67, p<.001\right]$. There was no triple interaction between these factors $(F<1)$. An ANOVA of the accuracy data only revealed a significant interaction between prime eccentricity and relatedness $[F(2,18)=5.41$, $\left.M S_{\mathrm{e}}=0.37, p<.01\right]$.

Pseudoletter analysis. The ANOVA on RTs revealed a main effect of repetition $\left[F(1,9)=5.74, M S_{\mathrm{e}}=959.20\right.$, $p<.05]$. In the accuracy data, there was a reliable interaction only between target eccentricity and repetition $\left[F(2,18)=5.62, M S_{\mathrm{e}}=0.19, p<.05\right]$.

\section{Discussion}

Experiment 2 demonstrates statistically equivalent repetition priming independent of prime and target location within a zone of central vision spanning $4.6^{\circ}$ $\left( \pm 2.3^{\circ}\right)$. Even with the most extreme separation, when prime and target occurred in opposite locations (to the

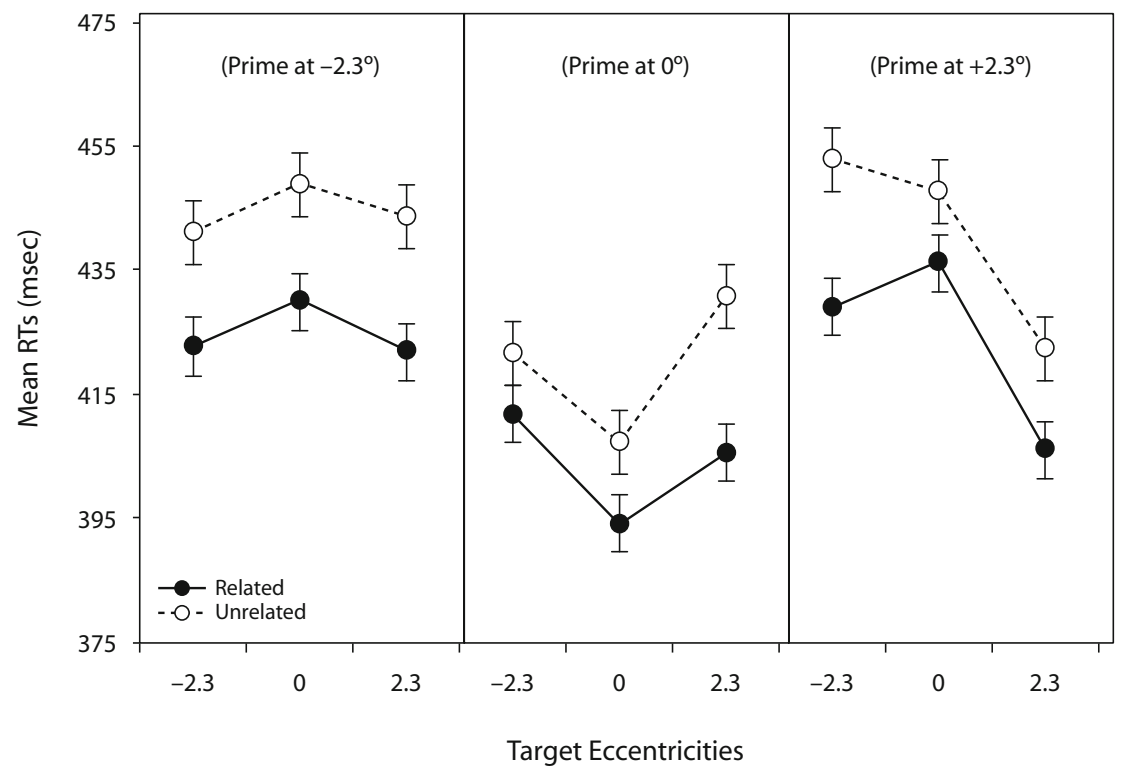

Figure 4. Mean reaction times (RTs) to target letters in Experiment 2, as a function of prime and target eccentricity. Values in the abscissa refer to target eccentricity. Solid circles give means for the related prime condition, open circles for the unrelated prime condition. Prime eccentricity is $-2.3^{\circ}$ in the left panel, $0^{\circ}$ in the middle panel, and $+2.3^{\circ}$ in the right panel. 


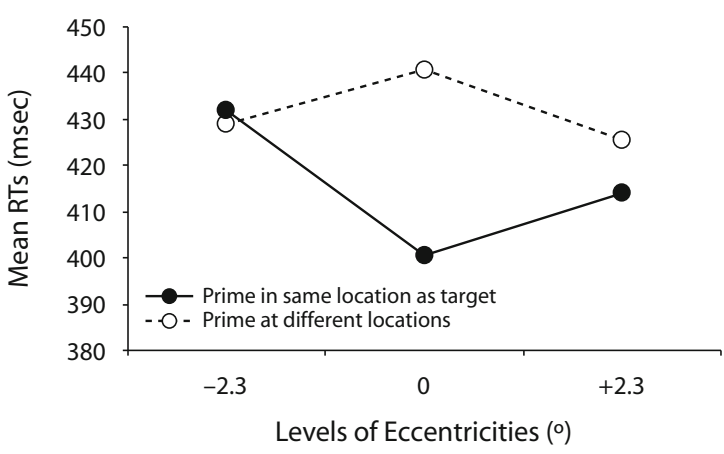

Figure 5. Mean reaction times (RTs) to target letters in Experiment 2 as a function of prime and target location, collapsed over prime-target relatedness.

left and to the right of fixation), priming effects were just as strong as when prime and target occurred at the same location. This result suggests that information about prime and target stimuli can be integrated across a relatively large area of central vision, at least for the letter stimuli used in the present study. Most importantly, the results of Experiment 2 suggest that it is not the distance separating primes and targets that critically determines the size of priming effects. If the absence of priming at $4^{\circ}$ prime eccentricities in Experiment 1B were due to the distance separating primes and centrally located targets, then we ought not to have found priming with primes and targets at opposite locations ( $4.6^{\circ}$ separation) in Experiment 2. It would therefore appear to be the eccentricity of the masked prime stimuli that is limiting priming effects in Experiment 1B, when primes and target occupy distinct locations. According to the attentional account of modulation of priming effects, attention is directed to the central location where all targets appeared in Experiment $1 \mathrm{~B}$, hence reducing the amount of attention directed to eccentric prime stimuli.

Experiment 2 also revealed an attentional influence on processing in conditions in which prime and target location varied independently. The pattern of average RTs suggests that primes can automatically attract attention due to their abrupt onset at a specific location in the visual field. Reponses to letter targets were faster when they appeared at the same location as primes, independently of primetarget relatedness. This cuing effect of prime stimuli (see Figure 5) only occurred for the central and rightward locations (40-msec cuing effect for center, $11 \mathrm{msec}$ for right, and $3 \mathrm{msec}$ for left). Prime stimuli automatically capture attention to a certain extent, hence reducing the amount of attention allocated to upcoming target stimuli that appear at a different location.

Experiment 2 revealed that only the attentional account can capture the observed data. The integration account predicted that the priming effect would be larger when prime and target locations match than when they do not. The results of Experiment 2 show that this was not the case. Furthermore, the attentional account can also accommodate the finding that RTs were faster (independently of prime relatedness) when primes and targets appeared at the same location. The attentional account can account for this finding, because it assumes that attention is drawn by the prime stimulus, which hurts performance if the target is presented in a different location than the prime.

\section{GENERAL DISCUSSION}

Experiment 1 of the present study provided a replication, with letter stimuli, of the influence of prime and target eccentricity on masked repetition priming found for word stimuli by Marzouki and Grainger (2008). When prime and target eccentricity covaried (Experiment 1A), there were main effects of eccentricity and priming and no interaction. Priming effects were, however, stronger for locations in the RVF. When targets were always centrally located and only prime location varied (Experiment 1B), repetition priming interacted with prime eccentricity such that priming effects diminished as prime eccentricity increased. Experiment 2 was designed to test two alternative accounts of this pattern (and the equivalent pattern for word stimuli reported by Marzouki \& Grainger, 2008), the integration versus the attentional account. According to the integration account, the influence of prime eccentricity on the size of priming effects is due to limitations in translation invariance (i.e., the capacity to integrate information across distinct spatial locations). According to the attentional account, centrally located targets result in an endogenous central focus of attention that diminishes from the center out. Lower levels of priming from eccentric primes would therefore be due to the lower levels of attention directed to those locations. To put these two accounts to test, prime and target location were varied independently in Experiment 2. Robust repetition priming was found that did not vary as a function of either prime or target location. In other words, contrary to the predictions of the integration account, priming was not any greater when prime and target location coincided than it was when they appeared at different locations. Furthermore, Experiment 2 revealed an influence of exogenous attention on performance, such that RTs were faster to targets that appeared at the same location as primes, and independently of prime-target relatedness. Despite the task instructions inviting participants to focus their attention on the central position, prime stimuli apparently acted as abrupt onsets leading to automatic attentional capture that overrode the endogenous effect of task instruction. The results of Experiment 2 are therefore in line with the predictions of the attentional account, but not the integration account.

\section{Spatial Attention and Masked Priming}

The results of the present study provide converging evidence for a primary role of spatial attention in modulating processing in priming paradigms in which prime and target stimuli occupy distinct locations. A number 
of prior studies have revealed attentional influences on masked repetition priming. Two experiments with word stimuli (Besner et al., 2005; Lachter et al., 2004) found priming when prime location did not coincide with the target location (primes appeared above or below target stimuli), but only when attention was attracted to the prime location by a preceding cue. Recently, Marzouki et al. (2007) also found that masked repetition priming of letter stimuli can be modulated by spatial attention. In this study, target letters always presented at a central location and primes appeared to the left or to the right of fixation. Marzouki et al. showed that target letter identification was affected by the allocation of spatial attention to the prime location by an exogenous cue. Priming only occurred when the exogenous cue appeared at the same peripheral location $\left( \pm 3.2^{\circ}\right)$ as the upcoming prime stimulus. Furthermore, priming effects were stronger in the RVF than in the LVF, suggesting a role for a general endogenous bias to the right, as is also revealed in the present study.

The attentional account supported by the present results is an account of the modulation of priming effect sizes as a function of prime and target location, but says nothing about how priming arises in the first place. Here we present a tentative account of masked repetition priming when primes and targets occupy different locations, and the role of attention in modulating these priming effects. The proposed model, shown in Figure 6, is an adaptation of Grainger and van Heuven's (2003) model of orthographic processing for the specific case of single letter stimuli.

The adaptation proposed here is based on the distinction between position-specific and position-independent letter detectors first proposed by Peressotti and Grainger (1995) in order to account for their masked priming effects obtained with letter triples. In the model described in Figure 6, location-specific letter detectors in the alphabetic array code for the presence of a given letter identity at a given location along the horizontal meridian. The location-specific letter detectors of the alphabetic array are designed for optimal processing of strings of letters, but are also engaged in the processing of single letters. When a single letter is presented, the appropriate location-specific letter detector is activated and sends activation on to the corresponding locationindependent letter detector that codes for the presence of a given letter, independently of its location. One important modification of the original Grainger and van Heuven (2003) model is that spatial attention modulates activity of location-specific letter detectors in the alphabetic array. Such attentional influences can be either endogenous or exogenous, hence accounting for the effects of maintaining target position constant in Experiment 1B, an endogenous influence, and the effects of prime cuing in Experiment 2, an exogenous influence. If one further assumes that it is activity in locationindependent letter detectors that determines speed and accuracy of responding in the alphabetic decision task, then this model accounts for why priming can be obtained when prime and target are presented at different locations, and why the size of priming effects is modulated by spatial attention.

\section{Attention and Reading}

Our results also have implications for basic processes in word recognition and reading. As mentioned in the

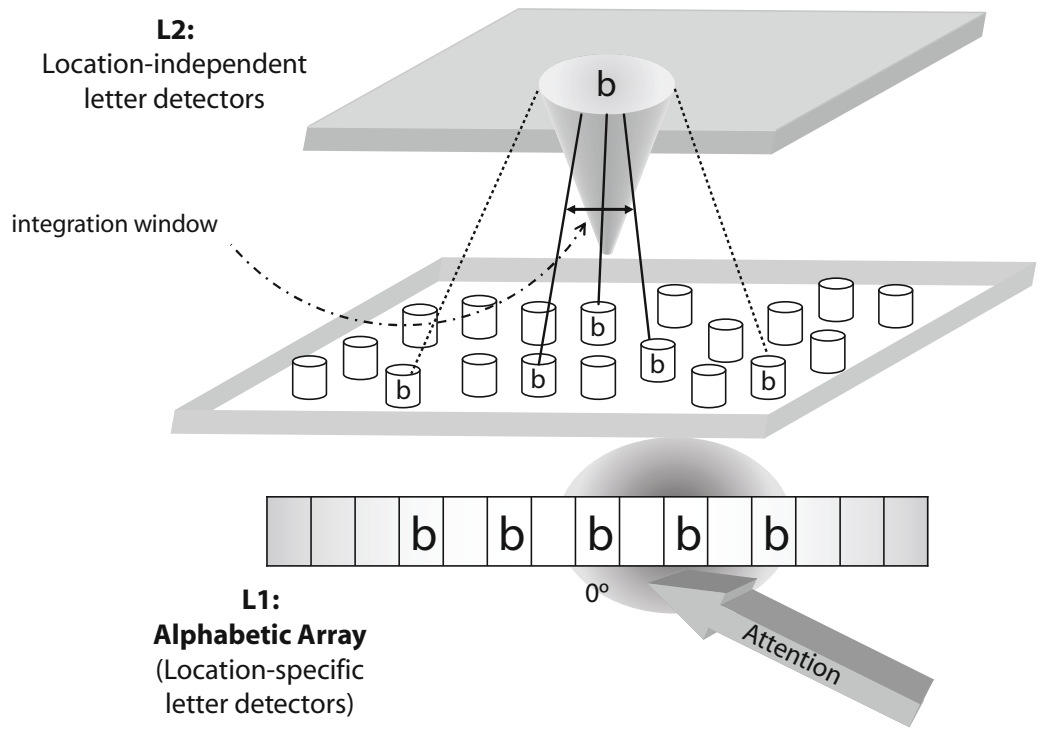

Figure 6. Adaptation of Grainger and van Heuven's (2003) model of orthographic processing for single-letter stimuli. Location-specific letter detectors (the alphabetic array) send activation forward to location-independent letter detectors. Activity in the alphabetic array is modulated by spatial attention. 
introduction, current models of reading differ in terms of the amount of parallel processing that can occur across several words and the role of attention in enabling processing of nonfixated stimuli. In the E-Z Reader model (Reichle et al., 1999), a shift of attention causes parafoveal stimuli to be processed, whereas in the SWIFT model (Engbert et al., 2005), processing is performed in parallel across several words without an attentional shift. In what follows, we suggest a combination of both of these models as a specific implementation of our account of effects of prime and target location on masked repetition priming.

As mentioned above and shown in Figure 6, in Grainger and van Heuven's (2003) model, reading-specific processing (i.e., following visual feature extraction) begins with a bank of letter detectors that perform parallel independent letter identification. These letter detectors are horizontally aligned and extend from the fovea into the periphery, thus enabling several words to be processed simultaneously. Given the drop in visual acuity as a function of eccentricity, on a given fixation, the letters in the currently fixated word will be the most visible (depending on the length of the word and fixation location within the word; Stevens \& Grainger, 2003). Processing extends beyond the currently fixated word, with visibility diminishing as a function of eccentricity, as in the SWIFT model. Grainger and van Heuven did not discuss the possible role of spatial attention in modulating letterlevel processing in their model, since they were primarily concerned with the recognition of single words. As shown in Figure 6, Grainger and van Heuven's model can be easily augmented with a mechanism for deployment of spatial attention. Spatial attention would provide a means to augment low-level orthographic processing of nonfixated stimuli and, more specifically, to-be-fixated words in the right parafovea. This account combines the acuity-dependent parallel processing of SWIFT with the sequential attention shifts of E-Z Reader. Shifts of spatial attention that are thought to augment parafoveal processing during normal reading (as in E-Z Reader) can also provide the mechanism for accommodating attentional influences on masked repetition priming found in the present study. However, contrary to E-Z Reader and in line with the SWIFT model, we propose that such attentional influences arrive on top of parallel independent letter processing that can span several words.

Finally, the results of the present study revealed an RVF bias that is consistent with prior research showing visual field asymmetries in visual word recognition (see Ducrot \& Grainger, 2007, for a review) and masked repetition priming effects (Marzouki et al., 2007). Attentional asymmetries induced by reading habits provide a unified account of these different visual field effects. Future research could test this hypothesis by replicating Marzouki and Grainger's (2008) study in a language read from right to left (e.g., Arabic or Hebrew).

\section{AUTHOR NOTE}

Correspondence concerning this article should be addressed to Y. Marzouki, Laboratoire de Psychologie Cognitive, Université d'Aix-Marseille, 3 Place Victor Hugo, 13331 Marseille Cedex 1, France (e-mail: yousri .marzouki@univ-provence.fr).

Note-Accepted by the editorial board of Editor-Elect Jeremy M. Wolfe.

\section{REFERENCES}

Besner, D., Risko, E. F., \& SkLAIR, N. (2005). Spatial attention as a necessary preliminary to early processes in reading. Canadian Journal of Experimental Psychology, 59, 99-108.

Ducrot, S., \& Grainger, J. (2007). Deployment of spatial attention to words in central and peripheral vision. Perception \& Psychophysics, 69, 578-590.

Engbert, R., Nuthmann, A., Richter, E., \& Kliegl, R. (2005). SWIFT: A dynamical model of saccade generation during reading. Psychological Review, 112, 777-813.

Forster, K. I., \& DAVIS, C. (1984). Repetition priming and frequency attenuation in lexical access. Journal of Experimental Psychology: Learning, Memory, \& Cognition, 10, 680-698.

Forster, K. I., \& Forster, J. C. (2003). DMDX: A Windows display program with millisecond accuracy. Behavior Research Methods, Instruments, \& Computers, 35, 116-124.

Grainger, J., \& VAN Heuven, W. (2003). Modeling letter position coding in printed word perception. In P. Bonin (Ed.), The mental lexicon (pp. 1-24). New York: Nova Science.

Holcomb, P. J., \& GRAINGER, J. (2006). On the time course of visual word recognition: An event-related potential investigation using masked repetition priming. Journal of Cognitive Neuroscience, 18, 1631-1643.

INHOFF, A. W. (1989). Lexical access during eye fixations in reading: Are word access codes used to integrate lexical information across interword fixations? Journal of Memory \& Language, 28, 444-461.

JACOBS, A. M., \& GraingER, J. (1991). Automatic letter priming in an alphabetic decision task. Perception \& Psychophysics, 49, 43-52.

Lachter, J., Forster, K. I., \& Ruthruff, E. (2004). Forty-five years after Broadbent: Still no identification without attention. Psychological Review, 111, 880-913.

Marzouki, Y., \& Grainger, J. (2008). Effects of prime and target eccentricity on masked repetition priming. Psychonomic Bulletin \& Review, 15, 141-148.

Marzouki, Y., Grainger, J., \& Theeuwes, J. (2007). Exogenous spatial cueing modulates subliminal masked priming. Acta Psychologica, 126, 34-45.

Peressotti, F., \& Grainger, J. (1995). Letter-position coding in random consonant arrays. Perception \& Psychophysics, 57, 875-890.

Pollatsek, A., Lesch, M., Morris, R. K., \& Rayner, K. (1992). Phonological codes are used in integrating information across saccades in word identification in reading. Journal of Experimental Psychology: Human Perception \& Performance, 18, 148-162.

Reichle, E. D., Rayner, K., \& Pollatsek, A. (1999). Eye movement control in reading: Accounting for initial fixation locations and refixations within the E-Z Reader model. Vision Research, 39, 4403-4411.

Segui, J., \& Grainger, J. (1990). Priming word recognition with orthographic neighbors: Effects of relative prime-target frequency. Journal of Experimental Psychology: Human Perception \& Performance, 16, 65-76.

SimON, J. R. (1969). Reactions toward the source of stimulation. Journal of Experimental Psychology, 81, 174-176.

Stevens, M., \& Grainger, J. (2003). Letter visibility and the viewing position effect in visual word recognition. Perception \& Psychophysics, 65, 133-151.

(Manuscript received January 22, 2008; revision accepted for publication April 23, 2008.) 